\title{
Use of satellite erythemal UV products in analysing the global UV changes
}

\author{
I. Ialongo ${ }^{1}$, A. Arola ${ }^{2}$, J. Kujanpää ${ }^{1}$, and J. Tamminen ${ }^{1}$ \\ ${ }^{1}$ Earth Observation, Finnish Meteorological Institute, Helsinki, Finland \\ ${ }^{2}$ Kuopio Unit, Finnish Meteorological Institute, Kuopio, Finland \\ Received: 11 April 2011 - Published in Atmos. Chem. Phys. Discuss.: 6 June 2011 \\ Revised: 12 September 2011 - Accepted: 14 September 2011 - Published: 16 September 2011
}

\begin{abstract}
Long term changes in solar UV radiation affect global bio-geochemistry and climate. The satellite-based dataset of TOMS (Total Ozone Monitoring System) and OMI (Ozone Monitoring Instrument) of erythemal UV product was applied for the first time to estimate the long-term ultraviolet (UV) changes at the global scale. The analysis of the uncertainty related to the different input information is presented. OMI and GOME-2 (Global Ozone Monitoring Experiment-2) products were compared in order to analyse the differences in the global UV distribution and their effect on the linear trend estimation.

The results showed that the differences in the inputs (mainly surface albedo and aerosol information) used in the retrieval, affect significantly the UV change calculation, pointing out the importance of using a consistent dataset when calculating long term UV changes. The areas where these differences played a major role were identified using global maps of monthly UV changes. Despite the uncertainties, significant positive UV changes (ranging from 0 to about $5 \% /$ decade) were observed, with higher values in the Southern Hemisphere at mid-latitudes during springsummer, where the largest ozone decrease was observed.
\end{abstract}

\section{Introduction}

The amount of solar ultraviolet (UV) radiation (200-400 nm) reaching the Earth's surface is affected by atmospheric ozone absorption, cloudiness and aerosols together with solar zenith angle (SZA) and surface albedo. On the global scale the UV levels at the surface decrease moving from the tropics to the polar regions due to the decrease of the maximum solar elevation angle and to the ozone increase with increas-

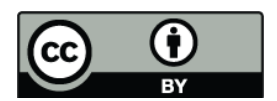

Correspondence to: I. Ialongo

(iolanda.ialongo@fmi.fi) ing latitude. Moreover, the presence of clouds and aerosols decreases the amount of radiation reaching the surface (Herman, 2010a).

Changes in UV radiation at the surface may strongly affect human health and terrestrial and aquatic ecosystems (UNEP, 2007). Erythemal dose rate (EDR), or erythemal irradiance, is one of the parameters used to estimate the damaging effects of solar UV radiation and is defined as the incoming solar radiation on a horizontal surface weighted with the erythemal action spectrum over the whole UV range (Diffey and McKinlay, 1987). Recently, Herman (2010b) used an improved radiation amplification factor to estimate the effect of total ozone changes on action spectrum weighted irradiances.

Surface UV radiation estimates have been provided from the Ozone Monitoring Instrument (OMI), flying on the NASA EOS Aura spacecraft since 15 July 2004. OMI is a Dutch-Finnish instrument designed to monitor ozone and other atmospheric species (Levelt et al., 2006). OMI UV products are local solar noon irradiances at 305, 310, 324, and $380 \mathrm{~nm}$, as well as EDRs and erythemal daily doses (EDDs). The OMI UV algorithm is based on the Total Ozone Monitoring System (TOMS) heritage (Krotkov et al., 1998, 2002; Tanskanen et al., 2006). TOMS and OMI UV data validation results were presented in several papers, analysing in details their strengths and weaknesses (Brogniez et al., 2005; Fioletov et al., 2002; Arola et al., 2005; Kazantzidis et al., 2009; Arola et al., 2009; Ialongo et al., 2010).

Satellite-based instruments with daily global coverage offer a geographical distribution suitable for global scale trend studies. TOMS and OMI together include UV and total ozone measurements from 1978 to 2010, and thus provide a unique dataset to analyse long-term changes in UV radiation at the surface and their relation to atmospheric ozone changes on the global scale. During the last several years, the ozone changes studies showed strong ozone decrease started in 1979 at mid and high latitudes with no significant changes in the tropical areas. The ozone levels then became stable

Published by Copernicus Publications on behalf of the European Geosciences Union. 
during the last 10 years but remaining well below the 1979levels (WMO, 2007). Consequently, the UV levels should be continuously monitored for their harmful effects on the biological systems.

Ziemke et al. (2000) examined the distribution of longterm trends in erythemal UV radiation for the period 19791991 using measurements from the Nimbus 7 TOMS instrument. Herman (2010a) estimated the global increase of UV radiation caused by ozone and reflectivity changes (including clouds and aerosols effects) during the period 1979-2008, using an approach based on Beer's law. The largest zonal average increases in UV irradiance were observed in the Southern Hemisphere ( $\mathrm{SH}$ ) where the ozone decrease has been the largest. These changes were only partially moderated by the decrease in aerosol transmission (i.e., the ratio of the transmitted to the total incident radiation) to the Earth's surface.

In this paper we investigate the first application of TOMS and OMI UV products to estimate global UV changes. The data are presented in Sect. 2. In Sect. 3 the methodology is explained. The description of the results, including the UV time series, the comparison between OMI and GOME-2 UV data and the UV linear trends, is presented in Sect. 4. Section 5 concludes the paper.

\section{Data}

\subsection{TOMS and OMI products}

The OMI instrument onboard the NASA EOS Aura spacecraft (on flight from 14 July 2004) is a nadir viewing spectrometer that measures solar reflected and backscattered light in a selected range of the UV and visible spectrum (Levelt et al., 2006). The Aura satellite describes a sun-synchronous polar orbit, crossing the equator at 13:45 local time. The width of the instrument's viewing swath is $2600 \mathrm{~km}$ and provides global daily coverage with a spatial resolution of $13 \times 24 \mathrm{~km}^{2}$ in nadir viewing. OMI measurements of ozone columns and profiles, aerosols, clouds, surface UV irradiance and the trace gases $\left(\mathrm{NO}_{2}, \mathrm{SO}_{2}, \mathrm{HCHO}, \mathrm{BrO}\right.$, and $\left.\mathrm{OClO}\right)$ are available at: http://mirador.gsfc.nasa.gov/.

In this work, both OMI and TOMS total ozone column, TO3 (see Bhartia et al. (2002) for information about the total ozone retrieval algorithm) and EDR data have been used. OMI Level-3 global gridded data (Version 3), with spatial resolution of $1 \times 1$ degree, were used.

The OMI surface UV retrievals are determined by means of an extension of the TOMS UV algorithm developed by NASA Goddard Space Flight Center (GSFC) (Tanskanen et al., 2006). Firstly, the algorithm estimates the surface irradiance under clear-sky conditions by using as inputs OMI satellite ozone data and climatological surface albedo. Afterwards the clear-sky irradiance is corrected by multiplying it with a cloud modification factor derived from OMI data that accounts for the attenuation of UV radiation by clouds and non-absorbing aerosols. The current OMI surface UV algorithm does not include absorbing aerosols, therefore OMI UV data are expected to show an overestimation for regions affected by absorbing aerosols (i.e., tropical regions or urban sites). Otherwise, the TOMS algorithm includes also a correction for the absorbing aerosols based on the aerosol index (AI) information. This means that OMI UV estimates could be higher than TOMS data over the regions affected by the absorbing aerosol.

Another relevant difference between TOMS and OMI is the albedo information used as input in the algorithms. TOMS uses the $360 \mathrm{~nm}$ Minimum Lambertian Equivalent Reflectivity (MLER) climatology as described by Herman and Celarier (1997). TOMS algorithm assumes that the seasonal surface albedo cycle is the same every year. At high latitudes, this assumption can lead to an underestimation of the surface albedo over temporary snow covered surfaces. To solve this problem, OMI uses the Moving Time-Window (MTW) albedo climatology based on the work of Tanskanen et al. (2003). The MTW method was applied to the TOMS $360 \mathrm{~nm}$ LER time-series during the period 1979-1992. At high latitudes the new climatology gave larger surface albedo than the MLER climatology, during the snow cover transition periods, where the MTW surface albedo is usually several percent larger than the climatological values (Tanskanen and Manninen, 2007). Higher surface albedo produces higher values of the surface UV estimates; thus, TOMS algorithm produces UV levels lower than OMI estimates over snow covered regions during transition periods.

The TOMS and OMI UV algorithms differ also for the ozone ghost column (signifying the amount of $\mathrm{O}_{3}$ under the clouds) height in the retrieval of $\mathrm{TO} 3$, which is used as input in the UV algorithm. TOMS TO3 data showed a $2 \%$ difference to OMI (TOMS TO3 higher than OMI), which can produce an additional effect on the trend calculation (Yang et al., 2008). These differences between OMI and TOMS algorithms will be further analysed in this paper.

\subsection{GOME-2 products}

The Global Ozone Monitoring Experiment-2 (GOME-2) is a scanning spectrometer that measures the light reflected from the Earth's surface and atmosphere. The spectrometer splits the light into its spectral components covering the UV/VIS region from $240 \mathrm{~nm}$ to $790 \mathrm{~nm}$ at a resolution of $0.2 \mathrm{~nm}$ to $0.4 \mathrm{~nm}$. The instrument is mounted on the European Metop-A satellite, which was launched in October 2006. The satellite flies on Sun-synchronous polar orbit (morning orbit 09:30 local time). GOME-2 continues the long-term monitoring of atmospheric properties started by GOME on ERS-2 and SCIAMACHY on Envisat. Concentrations of atmospheric $\mathrm{O}_{3}, \mathrm{NO}_{2}, \mathrm{SO}_{2}$ and further trace gases, together with cloud properties and UV radiation intensity, are provided. Each scan takes $6 \mathrm{~s}$ with a scan-width of $1920 \mathrm{~km}$, 
so that the global coverage can be achieved within 1.5 days. The ground pixel size is $80 \mathrm{~km} \times 40 \mathrm{~km}$ (GOME-2, 2009).

The UV processing algorithm involves the gridding of GOME-2 total ozone data, the inversion of cloud optical depth from reflectance data, and finally the calculation of surface UV quantities from radiative transfer model look-up tables. The GOME-2 UV products (available from the O3M SAF web-page http://o3msaf.fmi.fi) include the daily dose and maximum dose rates of integrated UV-B and UV-A radiation together with values obtained by different biological weighting functions and solar noon UV index (UVI).

For the estimation of diurnal cloud cover in the retrieval of the surface UV levels, the cloud optical thickness is derived from the Advanced Very High Resolution Radiometer (AVHRR) instrument onboard both Metop and NOAA satellites. As Metop is on a morning orbit and NOAA on an afternoon orbit, at least two samples of the diurnal cycle can be obtained globally.

The aerosol optical depths from a climatology combining satellite and AERONET data (Kinne, 2009) are used to account for the aerosol effect. The MTW surface albedo climatology is applied to regions with seasonally variable snow and/or ice cover. These regions are determined from the snow cover and sea ice extent maps of the National Snow and Ice Data Center (NSIDC). The MLER climatology is used for other regions.

\section{Method}

Noontime EDR data (also erythemal irradiance in the text) derived from TOMS and OMI were used to produce the global scale long term UV time series from 1978 to 2010. The data were monthly and zonally averaged using 5 degree latitude belts. The zonal averages minimize the effect of local phenomena, such as polluted urban sites or mountain areas.

The statistical distribution, with the monthly data within the zonal belts was analysed: it was observed that the distribution could be not always well described by the normal distribution, being the data skewed towards lower or higher values. As an example, in Fig. 1 the EDR histogram for the zonal belt $45^{\circ}-50^{\circ} \mathrm{N}$ on December 2008, together with the scaled normal and log-normal probability distribution function (PDF), are shown. In this case, the log-normal PDF (blue curve) represents better than the normal PDF (red curve), the actual distribution of the data. The median for a log-normal distribution can be derived as $e^{\mu}$ where $\mu=\operatorname{mean}(\log (x))$ and $x$ are the EDR values along the latitude band. The median values obtained using the normal and log-normal PDF differ by about $4 \%$, which is below the variability within the zonal belt (about $20 \%$ ).

Both mean and median were considered to estimate the zonal monthly average, intended as the estimate of the central tendency of the data: the median was selected as a more robust parameter in presence of outliers (Kyrölä et al., 2006).

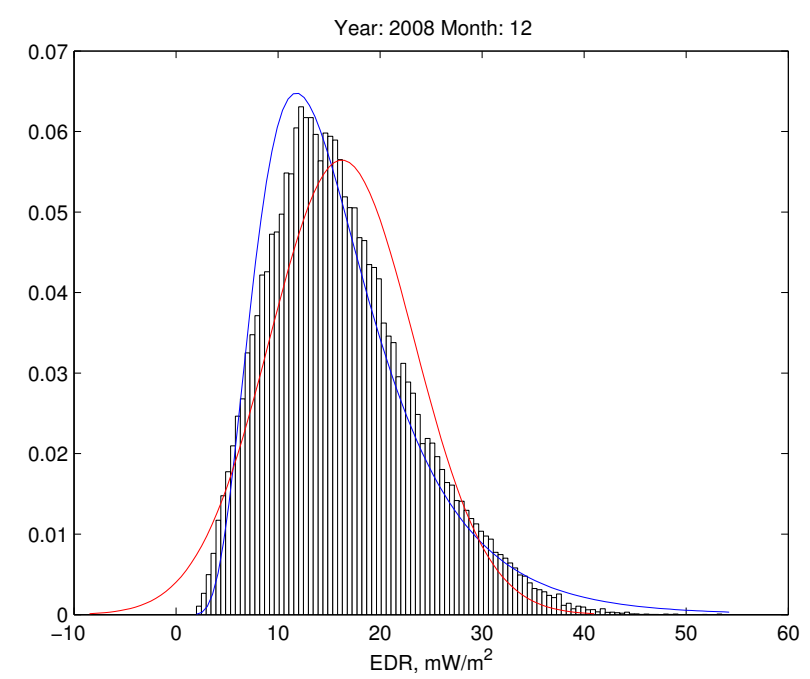

Fig. 1. EDR data distribution at $45^{\circ}-50^{\circ} \mathrm{N}$ zonal belt for December 2008. The red and the blue curves indicate the normal and the lognormal PDFs, respectively.

No deseasonalized EDRs were used for the trend analysis. The data during period with gaps were assumed to follow the linear trend obtained from the available data. The variability of the data was estimated from the interquartile range (IQR), and the percentage relative variability was estimated as $100 * I Q R / M e d i a n$. The value of IQR is calculated as $\mathrm{IQR}=\mathrm{Q} 3-\mathrm{Q} 1$, where $\mathrm{Q} 1$ and $\mathrm{Q} 3$ are the first and the third quartile, respectively.

An accurate filtering for missing data was applied in order to exclude the latitude belts with less than $50 \%$ of the pixels available for the zonal average. In the analysis it can be noticed that the missing data affect the areas at latitudes poleward of $50^{\circ} \mathrm{N}$ and $50^{\circ} \mathrm{S}$ during northern hemisphere (NH) and $\mathrm{SH}$ winters, respectively, corresponding to high SZAs.

The monthly UV and total ozone changes over the period 1978-2010 were calculated in terms of zonal linear trends per decade with latitude belts of $5^{\circ}$. Assuming that the linear equation can be written as $\boldsymbol{y}=a \boldsymbol{x}+b$, where the vector $\boldsymbol{x}$ includes the years and the vector $\boldsymbol{y}$ the UV monthly average for each year, the linear trend in percentage per decade (PD) and the associated error (PDE) can be calculated as:

$$
\begin{aligned}
& \mathrm{PD}=10 \times 100 \times(y(2)-y(1)) / y(1) \\
& \mathrm{PDE}=\mathrm{PD} \times \mathrm{se}_{a} / a
\end{aligned}
$$

where $a$ and se ${ }_{a}$ are the slope and its standard error, respectively.

In the regression analysis, the least squares approach was applied to find the best linear fit for the data, thus the equation of the straight line that minimizes the sum of squared 
residuals (i.e., the gradient of this sum of squares is null) defined as

$$
(\boldsymbol{y}-a \boldsymbol{x}-b)^{\prime} \times(\boldsymbol{y}-a \boldsymbol{x}-b),
$$

where the superscript in the first term indicates the transpose of the vector. In order to check the effect of the inhomogeneity of the zonal variance on the results, the weighted least squares was also applied. In this case, the squared residuals in the sum are multiplied by the weights as in the following expression:

$$
(\boldsymbol{y}-a \boldsymbol{x}-b)^{\prime} \times \mathbf{w} \times(\boldsymbol{y}-a \boldsymbol{x}-b),
$$

where $\mathbf{w}$ is the diagonal matrix of the weights, which are equal to the reciprocal of the variances of the samples.

The monthly UV linear trends per decade were also calculated for every $5 \times 5$ degrees latitude-longitude box, in order to locate the regions where the effect of the different input information (surface albedo or aerosol corrections) between OMI and TOMS algorithms, played a major role on the longterm UV change calculation. Thus, the monthly UV trend maps were produced.

Data gaps between 1992 and 1996 and 2002 and 2004 are due to a lack of data from Nimbus 7 and Earth Probe and from Earth Probe and OMI, respectively. The correlation coefficient $r$ and the $p$-value for the linear fit were also calculated to check if the results are statistically significant. The $p$-value is the probability of getting a correlation as large as the observed value by chance. If the $p$-value is smaller than 0.05 , then the correlation is significant at the $95 \%$ level. The results are shown in Sect. 4.

\section{Results}

\subsection{UV time series}

In Fig. 2, the EDR time-latitude plot is shown for the period 1979-2010. The data were monthly and zonally averaged in the latitude range from $60^{\circ} \mathrm{S}$ to $60^{\circ} \mathrm{N}$, using the median as a measure of the central tendency of the data. The UV data from 1979 to 1992 and from 1997 to 2001 correspond to TOMS data (Nimbus 7 and Earth Probe, respectively), while those from 2004 to 2010 to OMI data. Note the strong seasonality effect on the UV time evolution and higher EDR values in the SH summer, where the Earth's elliptical orbit is closer to the Sun and the average ozone at mid-latitudes is lower with respect to the $\mathrm{NH}$.

The monthly zonal variability (derived from the IQR) generally ranges from 0 to $15 \mathrm{~mW} \mathrm{~m}^{-2}$, with some peaks at $20-25 \mathrm{~mW} \mathrm{~m}^{-2}$. Larger variability was observed over the $\mathrm{SH}$; this is particularly significant over the tropical regions. The percentage relative variability shows values that generally range from 0 to $15 \%$, increasing from the equator to the mid-latitudes. The zonal belts over $50^{\circ}-60^{\circ} \mathrm{N}$ and $50^{\circ}-60^{\circ} \mathrm{S}$ showed the highest values, with peaks of $20 \%$ in variability.
This aspect, together with considerations about missing data (see Sect. 3), led us to remove these regions from the trend analysis.

\subsection{Intersatellite comparison between OMI and GOME-2 UV data}

The OMI EDR data were compared with GOME-2 UV products from 2007 to 2010. Before the comparison, the GOME2 data $0.5 \times 0.5$ degree pixels were regridded with $1 \times 1$ degree pixels, averaging the four GOME- 2 values within every OMI pixel.

As an example, in Fig. 3 is shown the zonal mean of the daily relative difference between OMI and GOME-2 EDR values every 1 degree of latitude, during 2008. The different panels show the comparison results for every month, from January to December. Only small differences (about $\pm 5 \%$ ) have been found over tropical regions, most likely related to the different ways to account for the aerosol effect. Large positive differences have been observed from $60^{\circ} \mathrm{S}$ to $90^{\circ} \mathrm{S}$, particularly during SH summer, due to the different assumptions concerning the treatment of the ice sheets (around the Antarctic continent) in the OMI and GOME-2 algorithms. Similarly, in the NH the effect of snow cover albedo produces large positive differences which extend to about $35^{\circ} \mathrm{N}$ during $\mathrm{NH}$ winter, likely because of the combined effect of the snow-covered surface albedo and the different cloud information used in the algorithms.

The zonal EDR data distribution of OMI data has been analysed in detail in comparison with GOME-2 UV products at $50^{\circ} \mathrm{N}$ during several days on February, when UV data from both instruments were available. The distributions (not plotted here) showed very similar features but large differences over several regions over land, where OMI shows very high values respect to GOME-2 (the relative difference of the average is about $15 \%$ ). This is related to the effect of nonpermanent snow cover over the land surface, which is not accounted for in the MLER albedo climatology, and will be analysed in Sect. 4.3. These OMI UV peaks contribute significantly to the zonal average calculation and can produce a larger positive trend when compared with TOMS EDR. The data showing a relative difference between OMI and GOME2 larger than about $10 \%$, were excluded from the trend analysis.

Additional differences between the two datasets can be related to the fact that in GOME-2 all the measurements taken at $\mathrm{SZA}>70^{\circ}$ are excluded, while in OMI SZAs up to $85^{\circ}$ are used. Different cloud cover assumptions in the OMI and GOME-2 algorithms can also contribute to the differences between the datasets. 


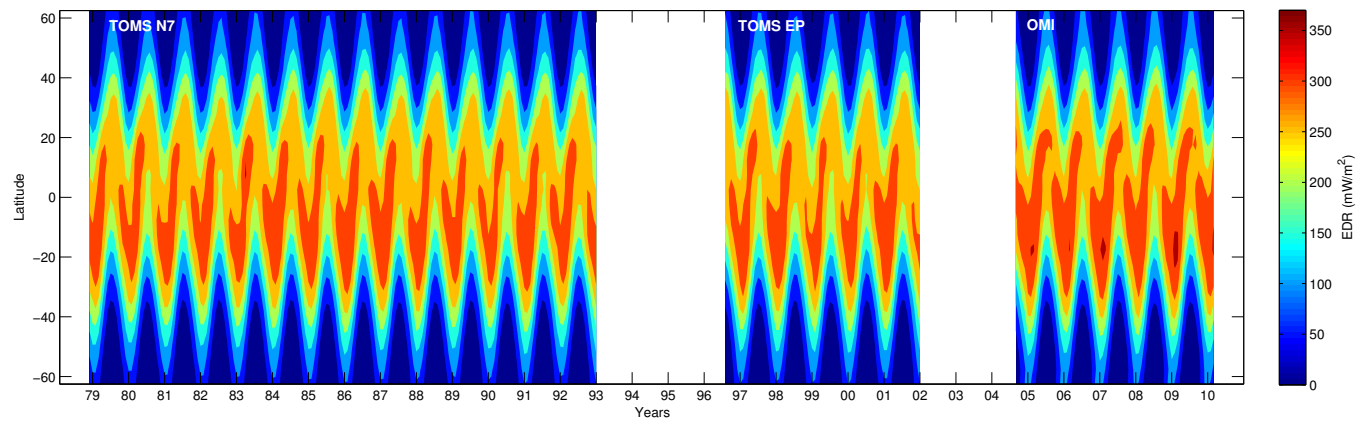

Fig. 2. EDR $\left(\mathrm{mWm}^{-2}\right)$ zonal monthly median time series from 1978 to 2010 every 5 latitude degrees from $60^{\circ} \mathrm{S}$ to $60^{\circ} \mathrm{N}$. The data from 1978 to 1992 are derived from TOMS - Nimbus 7, those from 1996 to 2001 from TOMS - Earth Probe and those from 2004 to 2010 from OMI.
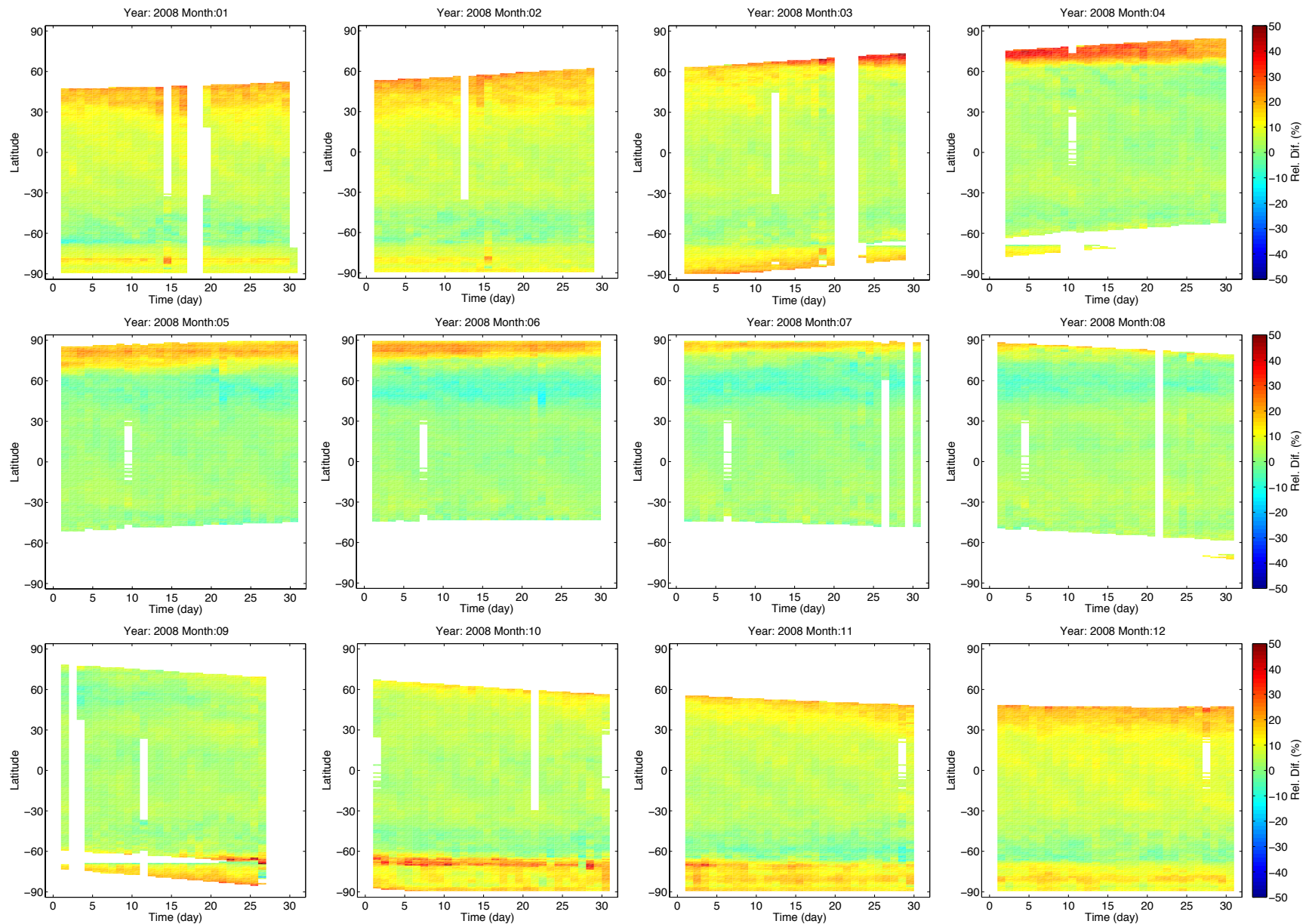

Fig. 3. OMI/GOME-2 EDR daily zonal mean relative difference during 2008. The red (blue) in the color scale indicates when OMI overestimates (underestimates) GOME-2 UV data. Different panels show different months from January to December, from left to right and from the upper to the lower row. 

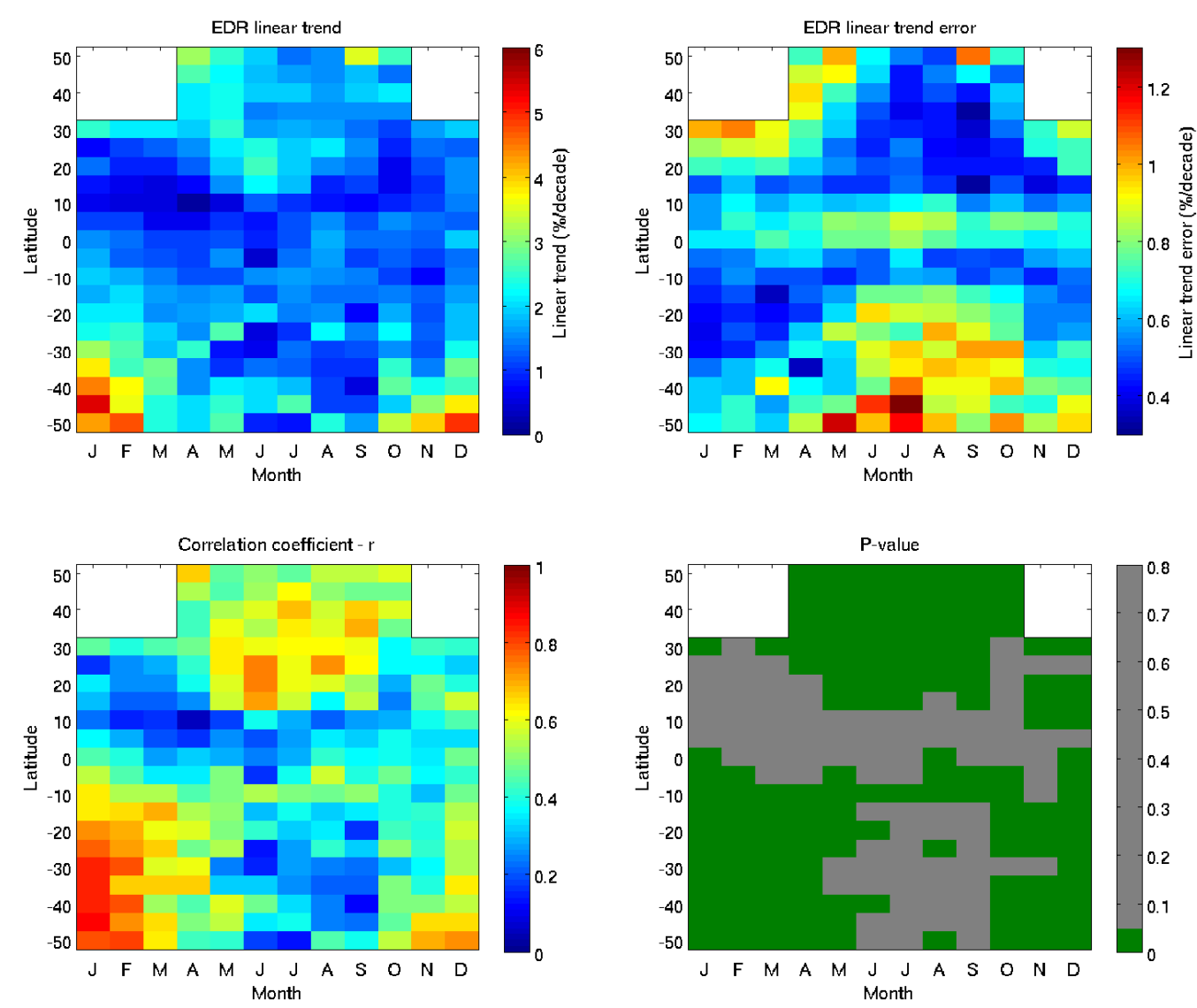

Fig. 4. UV zonal monthly linear trends (\%/decade) derived from TOMS and OMI EDR data from 1979 to 2010 (upper left panel), where the red color indicates the large positive trend values (up to $6 \% /$ decade) and the blue color indicates the trend values close to zero. The upper right panel shows the error on the linear trend (\%/decade), where the color scale from blue to red refers to the errors ranging from $0.3 \% /$ decade to $1.3 \% /$ decade. The correlation coefficient $r$ (red and blue indicate $r$ values close to 1 and 0 , respectively) and the $p$-value are shown in the lower left and right panels, respectively. The green pixels in the lower right panel indicate the statistically significant trends at the $95 \%$ level ( $p$-value $<0.05$ ); otherwise, the gray pixels refer to results not statistically significant. The data are zonally averaged every 5 degrees of latitude from $50^{\circ} \mathrm{N}-50^{\circ} \mathrm{S}$.

\subsection{UV global change results}

In Fig. 4 the zonal EDR linear regression results as a function of month and latitude belt every 5 degrees, are shown. The latitude range has been limited to $50^{\circ} \mathrm{S}-50^{\circ} \mathrm{N}$, according to what was discussed in Sect. 4.1. In addition, the results of the comparison between OMI and GOME-2 UV data showed that the higher differences were observed during the $\mathrm{NH}$ winter, because of the anomalous effect of the snow/ice albedo over land surfaces. Thus, the pixels between $30^{\circ} \mathrm{N}$ and $50^{\circ} \mathrm{N}$ from November to March were also excluded from the analysis as not realistic and appear as the white rectangles in Fig. 4. The UV trends obtained for these pixels would reach the unreliable value of $7 \% /$ decade, which does not correspond to a significant decrease in the ozone amount, during the same period and that is not consistent with the results obtained by Herman (2010a).
First, it can be observed that no UV negative zonal trends were obtained (Fig. 4 - upper left panel). The largest trends (up to about $5 \% / \mathrm{dec}$ ade) were found around $40^{\circ}-50^{\circ} \mathrm{S}$ from October to February. In the tropics the UV change values range from 0 to $2 \% /$ decade. The large positive UV trends observed over the SH in January/February are mainly due to the negative trends in the ozone observed in the same period. Analysing the time-latitude distribution of the error in the UV trend (Fig. 4 - upper right panel), the largest values can be found during winter, which involves small EDR values. The error values range from 0.3 to $1.3 \%$ /decade.

Looking at the correlation coefficient distribution (Fig. 4 - lower left panel), higher values were found during $\mathrm{NH}$ and SH summer. Correlation coefficients $r$ greater than 0.8 , were observed over the SH in January-February. In the NH, high $r$ values were found at mid-latitudes and during summer months over the tropics. The $p$-values distribution (Fig. 4 - lower right panel) confirms the correlation coefficient 
features and provides information about the significance of the trend results. No significant trends were observed in the equatorial area and over the $\mathrm{SH}$ in winter. Otherwise, significant values were found over SH during spring-summer months and over $\mathrm{NH}$ during summer.

The color scale in Fig. 4 (upper left panel) is dominated by the high values at $40^{\circ}-50^{\circ} \mathrm{S}$ from November to March; taking into account only the period from April to September, the significant trends range from 1.5 to $4 \% /$ decade mostly over the NH mid-latitudes. Otherwise, focusing the analysis on $\mathrm{NH}$ and $\mathrm{SH}$ summer, when the highest UV levels were observed, the trend values are much lower in the $\mathrm{NH}$ (maximum trend around $3.5 \% /$ decade) than in the SH (maximum trend around $5 \% /$ decade). Consistently, the largest ozone negative trends were observed in the $\mathrm{SH}$.

TO3 trend values range from 0 to $-3 \% /$ decade (Fig. 5). The UV trends are quite consistent with the TO3 trend patterns, so that negative TO3 trends correspond to positive UV trends. Some differences between UV and TO3 trend distributions could be related to cloud effects; the reduced cloud transmission observed over the last 30 years particularly in the SH (Herman, 2010a), could have reduced the UV increase produced by the ozone reduction. This does not happen in the $\mathrm{NH}$, where the mid-latitude transmission decrease was negligible, thus producing a difference in the UV response between the two hemispheres.

The results described above were obtained using the standard linear regression; these results were also compared to the results achieved by means of the linear weighted regression, using the inverse of the variances as weights. In Fig. 6 is plotted the month-latitude distribution of the difference between the linear trends obtained from the weighted linear regression and those obtained by the standard linear regression. The difference values range from -0.25 to $+0.45 \% /$ decade and remain always below the errors on the linear trend (see Fig. 4 - upper right panel). The larger is this difference, the bigger is the role of the zonal distribution variability in the trend calculation. The weighted regression affects also the error estimate, producing differences in the estimated error (not plotted here) ranging from about -0.1 to $0.02 \% /$ decade.

The UV trend distribution is consistent with the results obtained by Herman (2010a), using merged ozone data as input in UV model estimates. The trend patterns agree well in the tropical region and in the $\mathrm{NH}$, while there are some differences in the SH during April-May.

The zonal linear trends were also calculated using GOME2 UV products (not plotted here) instead of OMI, to estimate the effect of different input information in the UV estimates. The results showed a reduction in the trend values in the tropics (the average over the tropical region varies from about $1.3 \% /$ decade, using OMI, to $0.1 \% /$ decade, using GOME-2), where different aerosol information could play a role. Nevertheless, the results remained almost always statistically insignificant for the tropical regions. At midlatitudes, the trends obtained using GOME-2 data, showed

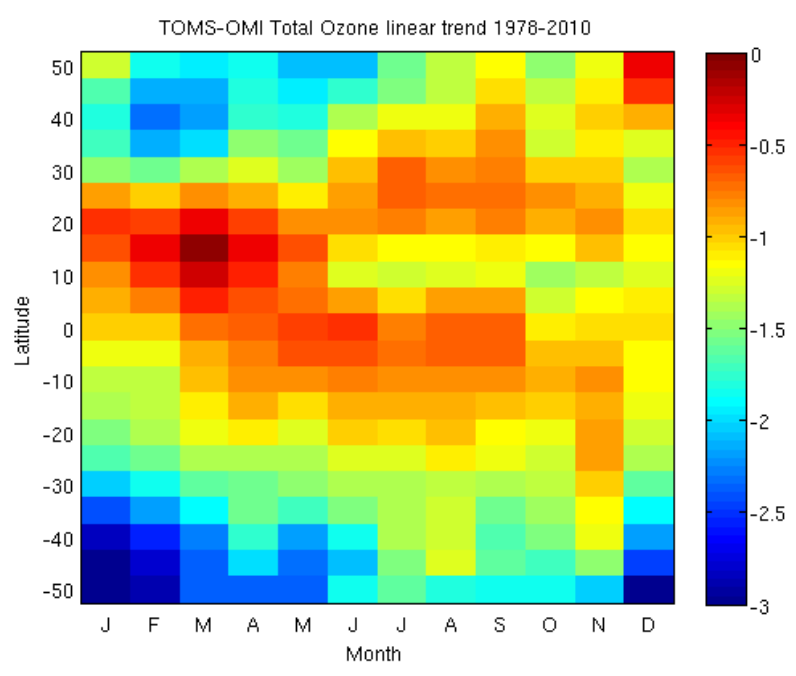

Fig. 5. Total Ozone zonal monthly linear trends (\%/decade) derived from TOMS and OMI data from 1979 to 2010. The red color indicates the trend values close to zero and the blue color the negative trend values (up to $-3 \% /$ decade). The data are zonally averaged every 5 degrees of latitude from $50^{\circ} \mathrm{N}-50^{\circ} \mathrm{S}$.

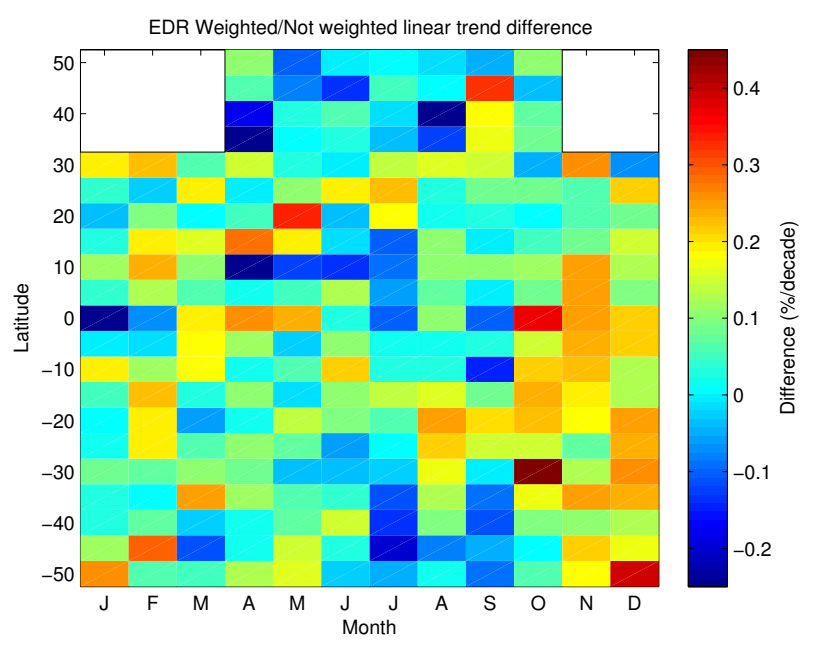

Fig. 6. Difference (\%/decade) between UV linear trends obtained from weighted and standard linear regression. The color scale from blue to red refers to the differences ranging from $-0.3 \% /$ decade to $0.5 \% /$ decade. The data are zonally averaged every 5 degrees of latitude from $50^{\circ} \mathrm{N}-50^{\circ} \mathrm{S}$.

similar high positive values in the SH during spring-summer, as in the OMI-based results, corresponding to the observed ozone decrease. Some differences were also observed: for example, larger positive trends (up to about $4 \% /$ decade) in the GOME2-based results at mid-latitudes from April to July in the $\mathrm{NH}$.

In order to identify the regions where the different input information played a major role in the trend calculation, the 

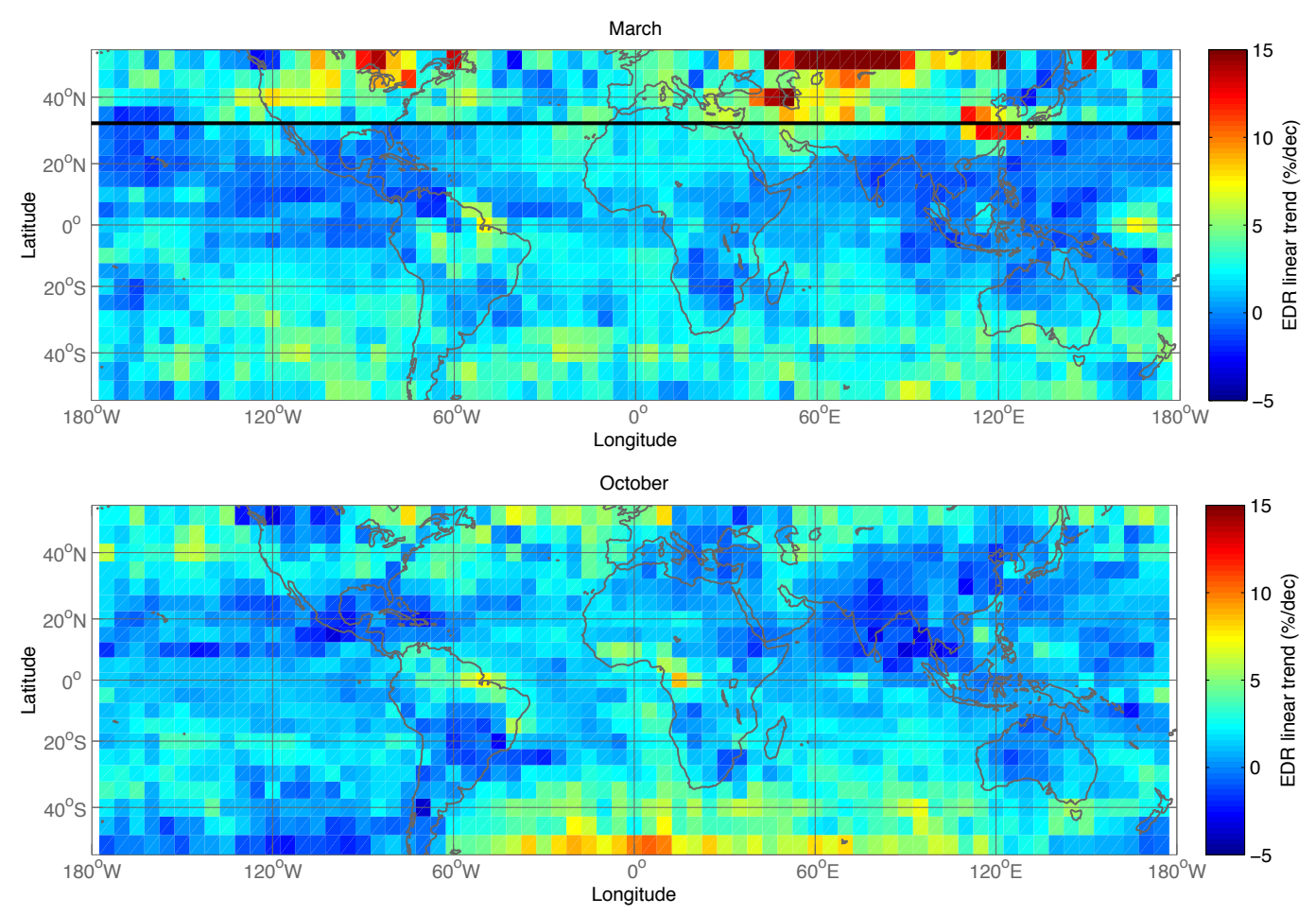

Fig. 7. Monthly UV linear trend (\%/decade) global maps for March and October (upper and lower panel, respectively). Red indicates large positive trends (up to $+15 \% /$ decade) while blue negative trends (up to $-5 \% /$ decade). The data are gridded in $5 \times 5$ deg boxes. The pixels above the black line $\left(32.5^{\circ} \mathrm{N}\right)$ were flagged out in Fig. 4 and appear there as white rectangles.

monthly UV trend (\%/decade) maps for March and October are shown in Fig. 7 (upper and lower panel, respectively). During March at NH mid-latitudes large values were observed over land, mainly related to the surface albedo assumption over snow-covered surfaces. The MTW albedo used in OMI is generally higher than TOMS MLER albedo where the non-permanent snow is observed, producing much larger UV values and thus large positive UV changes. Similar features were observed from November to March over the same areas. In Fig. 7 (upper panel) the pixels above the bold black line $\left(32.5^{\circ} \mathrm{N}\right)$ correspond to those flagged out in Fig. 4 (white rectangles). The large trend values reached the value of $15 \% /$ decade, which exceeded by about 10 percentage points the values obtained at the same latitude over sea. Thus, the inter-satellite differences between OMI and TOMS discussed here, add an additional uncertainty to the one presented in figure 4 (upper right panel).

Furthermore, large values were observed also over extensive areas in Eastern China, including Beijing and the Sichuan basin, where the UV change is driven most likely by the aerosol effect. In particular, over these areas the large amount of scattering aerosols produced an overestimation of the MTW surface reflectance estimates. The high aerosol load that should decrease surface UV radiation amount, produced high surface albedo values, thus increasing the modeled UV levels. In addition, the absorbing aerosols, which are not taken into account in the current OMI algorithms, can lead to an additional overestimation in the OMI UV level, which in turn produces a positive UV change, when TOMS and OMI data are combined. The aerosol index and the reflectivity values over these areas over Eastern-China are often those required for the application of the TOMS absorbing aerosol correction (these values are $\mathrm{AI}>0.5$ and reflectivity $<0.15$ ).

In October the ozone hole effect around $40^{\circ}-50^{\circ} \mathrm{S}$ is visible (note the zonal asymmetry due to the polar vortex displacement in Fig. 7 - lower panel). At the tropics a slight effect of the differences in the absorbing aerosol treatment can be observed, most likely related to biomass burning (South America) and desert dust (West-Africa).

\section{Conclusions}

The use of satellite UV products for estimating the global long-term UV change was investigated in this paper. In particular, the effects of the input information used in the UV retrieval were analysed in order to estimate the reliability of the UV change results.

Satellite UV products from TOMS and OMI were used to produce the UV time series from the mid-latitudes to the tropics. A strong seasonality was observed, with high EDR 
values in the SH summer, where the Earth's elliptical orbit is closer to the Sun and the average ozone at the mid-latitude is lower, with respect to the $\mathrm{NH}$. The monthly zonal variability has been defined from the interquartile range; the values range from 0 to $15 \mathrm{~mW} \mathrm{~m}^{-2}$, with peaks at $20-25 \mathrm{~mW} \mathrm{~m}^{-2}$. In terms of percentage relative zonal variability, the values range from 0 to $15 \%$, increasing from the equator to the midlatitudes.

The comparison between OMI and GOME-2 EDR data generally showed a good agreement (differences within $\pm 10 \%$ at tropics/mid-latitudes), also showing the differences between the two algorithms. The main differences are observed over the Antarctic continent ice-sheets or over the snow-covered land surface at $\mathrm{NH}$ mid-latitudes and are related to the different surface albedo assumptions. GOME-2 data were also very useful to analyse the effect of the different assumptions of the input parameters, such as aerosol and surface albedo, when TOMS and OMI data are combined for the linear trend calculation.

Satellite UV data have been used to calculate the erythemal UV change (\%/decade) over 32-years from 1979 to 2010, applying the linear regression method every month at several zonal belts. Thus, a time-latitude map of the linear trend results has been produced; only positive UV trends were observed. The largest trends (up to about $5 \% /$ decade) have been found at SH mid-latitudes during spring-summer, where the largest negative trend in the total ozone has been observed. In the tropics the UV trend values are limited to the range $0-2 \% /$ decade and are mostly not statistically significant as observed in the ozone changes. The error in the UV trend estimates was determined, with error values ranging from 0.3 to $1.3 \% /$ decade. In general, the UV trends are consistent with the total ozone trends, being the ozone anticorrelated with UV.

The comparison between the trends obtained using OMI or GOME-2 in combination with TOMS showed the largest differences during $\mathrm{NH}$ autumn-winter at mid-latitudes, pointing out that the differences in the surface albedo information play the major role in these differences. The trend values obtained using OMI or GOME-2 data differ by up to $5 \% /$ decade.

Being the main scope of the paper the analysis of the sources of uncertainty in using an UV long term dataset from different instruments, the analysis of the different natural proxies such as the annual and semiannual variability, the solar cycle and the quasi-biennial oscillation (QBO), were not taken into account at this stage.

The effect on the trend calculation of the inhomogeneous variability within the zonal belt was analysed applying the weighted linear regression. The differences between the weighted and non-weighted linear regression results range from -0.25 to $+0.45 \% /$ decade; the relative difference is typically from -10 to $10 \%$, with peaks around $30 \%$ over the $\mathrm{NH}$ tropics. The larger is the difference the bigger is the effect on the trend calculation of the variability within the zonal belt. The weighted regression affects also the error es- timate, producing differences in the estimated error ranging from about -0.1 to $0.02 \% /$ decade. This difference remains still below the uncertainty given on the trend estimates.

The monthly maps of the UV change, derived every $5 \times 5$ latitude-longitude degrees showed that the sources of uncertainty in the trend calculation are mostly related to the effect of the aerosols, which affects the zonal average values over particular regions (such as areas over the Sahara, South America and Beijing-East China) and to the snow-ice surface albedo during transition periods (i.e., over Canada and Northern Russia), which produced significant differences when OMI and TOMS data were used together for the trend calculation.

Discarding data at latitudes higher than $35^{\circ} \mathrm{N}$ pointed out the importance of using a homogeneous dataset (i.e., using the same input information in both instrument algorithms) when calculating the long term UV changes.

Edited by: W. Lahoz

\section{References}

Arola, A., Kazadzis, S., Krotkov, N., Bais, A., Gröbner, J., and Herman, J. R.: Assessment of TOMS UV bias due to absorbing aerosols, J. Geophys. Res., 110, D23211, doi:10.1029/2005JD005913, 2005.

Arola, A., Kazadzis, S., Lindfors, A., Krotkov, N., Kujanpää, J., Tamminen, J., Bais, A., di Sarra, A., Villaplana, J. M., Brogniez, C., Siani, A. M., Janouch, M., Weihs, P., Webb, A., Koskela, T., Kouremeti, N., Meloni, D., Buchard, V., Auriol, F., Ialongo, I., Staneck, M., Simic, S., Smedley, A., and Kinne, S.: A new approach to correct for absorbing aerosols in OMI UV, Geophys. Res. Lett., 36, L22805, doi:10.1029/2009GL041137, 2009.

Bhartia, P. K. and Wellemeyer, C. W.: TOMS-V8 total O3 algorithm, NASA Goddard Space Flight Center, Greenbelt, MD, OMI Algorithm Theoretical Basis Document Vol II., 2002.

Brogniez, C., Houët, M., Siani, A. M., Weihs, P., Allaart, M., Lenoble, J., Cabot, T., de la Casiniere, A., and Kyrö, E.: Ozone column retrieval from solar UV measurements at ground level: Effects of clouds and results from six European sites, J. Geophys. Res., 110, D24202, doi:10.1029/2005JD005992, 2005.

Diffey, B. and McKinlay, A. F.: A reference action spectrum for ultraviolet induced erythema in human skin, Human Exposure to UV radiation: Risks and Regulations, 83-87, Elsevier, NY, 1987.

Fioletov, V.E., Kerr, J. B., Wardle, D. I., Krotkov, N., and Herman, J. R.: Comparison of Brewer ultraviolet irradiance measurements with total ozone mapping spectrometer satellite retrievals, Opt. Eng., 41, 3051-3061, 2002.

GOME-2 Products Guide: EUM/OPS-EPS/MAN/07/0445, Issue/Revision 2/D, 2009.

Herman, J. R.: Global increase in UV irradiance during the past 30 years (1979-2008) estimated from satellite data, J. Geophys. Res., 115, D04203, doi:10.1029/2009JD012219, 2010a.

Herman, J. R.: Use of an improved radiation amplification factor to estimate the effect of total ozone changes on action spectrum weighted irradiances and an instrument response function, J, Geophys. Res., D23119, doi:10.1029/2010JD014317, 2010b. 
Herman, J. R. and Celarier, E. A.: Earth surface reflectivity climatology at 340-380 nm from TOMS data, J. Geophys. Res., 102, 28003-28011, 1997.

Ialongo, I., Buchard, V., Brogniez, C., Casale, G. R., and Siani, A. M.: Aerosol Single Scattering Albedo retrieval in the UV range: an application to OMI satellite validation, Atmos. Chem. Phys., 10, 331-340, doi:10.5194/acp-10-331-2010, 2010.

Kazadzis, S., Bais, A., Arola, A., Krotkov, N., Kouremeti, N., and Meleti, C.: Ozone Monitoring Instrument spectral UV irradiance products: comparison with ground based measurements at an urban environment, Atmos. Chem. Phys., 9, 585-594, doi:10.5194/acp-9-585-2009, 2009.

Kinne, S.: Climatologies of cloud related aerosols: Part 1: Particle number and size, in Clouds in the Perturbed Climate System, edited by: Heintzenberg, J. and Charlson, R. J., chap. 3, 37-58, MIT Press, Cambridge, Mass, 2009.

Krotkov, N. A., Bhartia, P. K., Herman, J. R., Fioletov, V., and Kerr, J.: Satellite estimation of spectral surface UV irradiance in the presence of tropospheric aerosols: 1 . Cloud-free case, J. Geophys. Res., 103(D8), 8779-8793, 1998.

Krotkov, N. A., Herman, J. R., Bhartia, P. K., Seftor, C., Arola, A., Kaurola, J., Koskinen, L., Kalliskota, S., Taalas, P., and Geogdzhaev, I.: Version 2 TOMS UV algorithm: Problems and enhancements, Opt. Eng., 41(12), 3028-3039, 2002.

Kyrölä, E., Tamminen, J., Leppelmeier, G. W., Sofieva, V., Hassinen, S., Seppälä, A., Verronen, P. T., Bertaux, J.-L., Hauchecorne, A., Dalaudier, F., Fussen, D., Vanhellemont, F., d'Andon, O. F., Barrot, G., Mangin, A., Theodore, B., Guirlet, M., Koopman, R., Saavedra, L., Snoeij, P., and Fehr, T.: Nighttime ozone profiles in the stratosphere and mesosphere by the Global Ozone Monitoring by Occultation of Stars on Envisat, J. Geophys. Res., 111, D24306, doi:10.1029/2006JD007193, 2006.
Kyrölä, E., Tamminen, J., Sofieva, V., Bertaux, J. L., Hauchecorne, A., Dalaudier, F., Fussen, D., Vanhellemont, F., Fanton d'Andon, O., Barrot, G., Guirlet, M., Fehr, T., and Saavedra de Miguel, L.: GOMOS O3, NO2, and $\mathrm{NO}_{3}$ observations in 2002-2008, Atmos. Chem. Phys., 10, 7723-7738, doi:10.5194/acp-10-77232010, 2010.

Levelt, P. F., van den Oord, G. H. J., Dobber, M. R., Mälkki, A., Visser, H., de Vries, J., Stammes, P., Lundell, J., and Saari, H.: The Ozone Monitoring Instrument, IEEE Trans. Geo. Rem. Sens, 44(5), 1093-1101, 2006.

Tanskanen, A. and Manninen, T.: Effective UV surface albedo of seasonally snow-covered lands, Atmos. Chem. Phys., 7, 27592764, doi:10.5194/acp-7-2759-2007, 2007.

Tanskanen, A., Arola, A., and Kujanpää, J.: Use of the moving time-window technique to determine surface albedo from the TOMS reflectivity data, in: Proc. SPIE, 4896, 239-250, 2003.

Tanskanen, A., Krotkov, N. A., Herman, J. R., and Arola, A.: Surface Ultraviolet Irradiance from OMI, IEEE Trans. Geo. Rem. Sens. Aura Special Issue, 2006.

UNEP: Environmental effects of ozone depletion and its interactions with climate change, 2006 assessment, Photoch. Photobio. Sci., 6(3), 201-332, 2007.

WMO (World Meteorological Organization): Scientific assessment of ozone depletion: 2006, Global Ozone Res. and Monit. Proj. Rep. 50, Geneva, 2007.

Yang, K., Krotkov, N. A., Bhartia, P. K., Joiner, J., McPeters, R. D., Krueger, A. J., Vasilkov, A., Taylor, S., Haffner, D., and Chiou, E.: Satellite Ozone Retrieval with Improved Radiative Cloud Pressure, In Proc. Quadrennial Ozone Symposium, Tromso, Norway, 2008.

Ziemke, J. R., S. Chandra, J. Herman, and C. Varotsos: Erythemally weighted UV trends over northern latitudes derived from Nimbus 7 TOMS measurements, J. Geophys. Res., 105(D6), 7373-7382, doi:10.1029/1999JD901131, 2000. 